\title{
Correction to: Novel design and simulation of reversible ALU in quantum dot cellular automata
}

\section{Behrouz Safaiezadeh ${ }^{1}$. Ebrahim Mahdipour ${ }^{1}$. Majid Haghparast ${ }^{2}$ (1) . Samira Sayedsalehi ${ }^{3} \cdot$ Mehdi Hosseinzadeh $^{4,5}$}

Published online: 15 June 2021

(C) Springer Science+Business Media, LLC, part of Springer Nature 2021

\section{Correction to: The Journal of Supercomputing https://doi.org/10.1007/s11227-021-03860-y}

Due to a typesetting mistake, the article was published with an error in one of the affiliations.

The 5 th affiliation was corrected to

Computer Science, University of Human Development, Sulaymaniyah, Iraq

No other changes to the article have been made. We apologise for any inconvenience caused to our readers.

Publisher's Note Springer Nature remains neutral with regard to jurisdictional claims in published maps and institutional affiliations.

The original article can be found online at https://doi.org/10.1007/s11227-021-03860-y.

Majid Haghparast

haghparast@srbiau.ac.ir

1 Department of Computer Engineering, Science and Research Branch, Islamic Azad University, Tehran, Iran

2 Department of Computer, Yadegar-E-Imam Khomeini (RAH) Shahre Rey Branch, Islamic Azad University, Tehran, Iran

3 Department of Computer Engineering, South Tehran Branch, Islamic Azad University, Tehran, Iran

4 Institute of Research and Development, Duy Tan University, Da Nang 550000, Vietnam

5 Computer Science, University of Human Development, Sulaymaniyah, Iraq 